\section{Ativismo LGBT organizacional: debate e agenda de pesquisa ${ }^{1}$}

\author{
Danuzio Weliton Gomes da Silva, Gustavo Henrique Carvalho de Castro \\ e Marcus Vinicius Soares Siqueira
}

\section{RESUMO}

Este trabalho analisa o debate sobre ativismo LGBT nas organizações. Inicialmente, elaborou-se um panorama da produção científica internacional, identificando contribuições, estruturas e objetivos dos ativismos e aspectos teórico-metodológicos. Baseado nisso, formulou-se agenda pautada nas sugestões e discussões. Para tanto, realizou-se levantamento bibliográfico na base Scopus de 2010 a 2019, submetendo artigos coletados a protocolo de revisão sistemática de literatura. Os resultados indicaram que essa pesquisa tem impulso nascente e privilegia, dentre os LGBT, sujeitos gays. Os estudos são amparados em diferentes referenciais teóricos e mais relacionados ao paradigma interpretativista. Prevaleceu o ativismo LGBT classificado como "abordagem informal internamente responsiva" (Githens \& Aragon, 2009), com efeitos de bem-estar psicológico e maior possibilidade de ganhos de igualdade de direitos para sexualidades dissidentes em organizações que possuem ativismo. Novos caminhos podem estimular futuros estudos relacionados à temática no Brasil, tais como: mecanismos de voz; impactos na mudança organizacional; aspectos políticos e culturais; e utilização de metodologias mais críticas. A principal contribuição do estudo está em ser pioneiro ao tratar do ativismo LGBT, detectando linhas específicas para sua investigação em estudos organizacionais nacionais.

Palavras-Chave: ativismo LGBT nas organizações; grupos de afinidades; redes de empregados; grupos de recursos de empregados; revisão de literatura.

\section{Organizational LGBT activism: debate and research agenda}

\section{ABSTRACT}

This paper analyzes the debate on LGBT activism in organizations. It elaborated an overview of international scientific production, identifying contributions, structures and objectives of activisms and theoretical-methodological approaches. Based on this, an agenda based on suggestions and discussions was formulated. To this end, a bibliographic survey was carried out on the Scopus database from 2010 to 2019, submitting collected articles to a systematic literature review protocol. The results indicated that this research has a nascent impulse and privileges, among LGBT persons, gay subjects. The studies are supported by different theoretical references and more related to the interpretive paradigm. Prevailed LGBT activism classified as "informal internally responsive approach" (Githens \& Aragon, 2009), with effects of psychological well-being and greater possibility of equal rights gains for dissident sexualities in organizations that have activism. New paths may stimulate future studies related to theme in Brazil, such as: voice mechanisms; impacts on organizational change; political and cultural aspects; and use of more critical methodologies. The main contribution of the study is to be a pioneer in dealing with LGBT activism, detecting specific lines for its investigation in national organizational studies.

Keywords: LGBT activism in organizations; affinity groups; employee networks; employee resource groups; review of literature.

1 Agradecemos ao apoio concedido pela CAPES (Código de Financiamento: 001) e aos avaliadores deste trabalho pelos seus comentários e sugestões, visto que estes enriqueceram significativamente a versão final do artigo.
Recebido em: 15/06/2020 Revisado em: 30/07/2020 Aprovado em: 28/09/2020

Check for updates

Danuzio Weliton Gomes da Silva (iD,

Universidade Federal Rural de Pernambuco, Brasil

Doutor em Administração,

Universidade de Brasília, Brasil

danuzioweliton@hotmail.com

Gustavo Henrique Carvalho de Castro (iD,

Universidade de Brasília, Brasil Doutorando em Administração, Universidade de Brasilia, Brasil

gustavo.hc.castro@gmail.com

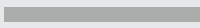

Marcus Vinicius Soares Siqueira (iD,

Universidade de Brasilia, Brasil Doutor em Administração, Escola de Administração de Empresas de São Paulo, Fundação Getúlio Vargas, Brasil

marc-vs@uol.com.br 


\section{Introdução}

Tendo em vista os diversos avanços sociais em termos de diversidade sexual e de gênero, as organizações têm criado ou incrementado políticas organizacionais voltadas a empregados e empregadas Lésbicas, Gays, Bissexuais, Transexuais, Travestis e Transgêneros (LGBT). Porém, esse contexto ainda é repleto de mensagens contraditórias em termos de políticas e práticas (Anteby \& Anderson, 2014; Diniz, Carrieri, Gandra, \& Bicalho, 2013; Martinez, Sawyer, \& Wilson, 2017; Saraiva \& Irigaray, 2009; Souza, Silva, \& Carrieri, 2012), visto que a manutenção de práticas discriminatórias no ambiente de trabalho repercute negativamente não somente na vida profissional e na carreira, mas também em níveis de satisfação e cidadania (McFadden, 2015; Siqueira, Saraiva, Carrieri, Lima, \& Andrade, 2009).

Em face dessa vulnerabilidade - que oprime trabalhadores, induzindo à ocultação de suas expressões de sexualidade, restrição a promoções, assédio e até mesmo demissão (McFadden, 2015) -, é que emergem, no seio das organizações, redes internas de apoio que podem dotar empregados LGBT de apoio psicossocial, auxiliando, inclusive, no debate acerca de atitudes no trabalho, oportunidades de carreira, dentre outras ações (Siqueira \& Andrade, 2012; Trau, 2015), o que pode ser caracterizado como ativismo LGBT organizacional (Githens \& Aragon, 2009; Raeburn, 2004). Dessa forma, grupos LGBT, historicamente dominados, também são capazes de fazer das instâncias de opressão lugares de resistência (Louro, 1997).

O ativismo de empregados apareceu pela primeira vez em corporações dos Estados Unidos, durante os anos 1970 e 1980, relacionado a questões de raça (Briscoe, Chin, \& Hambrick, 2014). Porém, o grande salto na visibilidade e na organização da atuação gay e lésbica no trabalho data dos anos 1990, conforme clássico estudo de Raeburn (2004). Surgiram oportunidades políticas e institucionais; houve cobertura sem precedentes da mídia sobre ativismo queer e discriminação no emprego; em combinação com mudanças institucionais em direção à diversidade corporativa e a benefícios equitativos. Após relativo isolamento do movimento institucional, os ativistas trabalharam arduamente para promover vínculos interorganizacionais entre homossexuais e redes de empregados. Essas conexões variaram de encontros sociais informais e intercâmbios de e-mail para mecanismos de rede totalmente institucionalizados, como conferências anuais sobre o local de trabalho e grupos guarda-chuva formais, consistindo em diversos formatos de redes (Raeburn, 2004).

O ativismo LGBT em organizações tem sido associado a termos como "grupos de recursos de empregados", "redes de empregados" ou "grupos de afinidade" (Githens \& Aragon, 2009; McFadden \& Crowley-Henry, 2017), ou mesmo mencionado como ativismo de pessoas LGBT e seus aliados dentro e fora das organizações (Colgan \& McKearney, 2012). É possível compreender tal temática como movimento social em que são formados grupos com diversos objetivos e de várias formas, de modo a influenciar comportamento e concomitantemente mudança nas organizações. Tais grupos têm potencial para ampliar a voz LGBT e gerar mensagens coletivas que podem confrontar estruturas que desqualificam e enfraquecem grupos minoritários. 
Empregados LGBT ativistas tendem a advogar por mudanças no ambiente de trabalho, recrutam apoiadores e mobilizam recursos, de modo a promover a igualdade de direitos e oportunidades, tentando compatibilizar seus objetivos à cultura corporativa, evitando choques com a gestão. Utilizam-se da lógica de business case - "[...] expectativa de que as organizações que gerenciam bem a diversidade também melhorem seu desempenho" (Oberfield, 2014, p. 777, tradução nossa) -, na qual se privilegia o suporte social à afirmação das sexualidades ditas "desviantes" e tenta-se compatibilizar as demandas e lutas com ganhos comerciais e estratégicos para a organização (Briscoe et al., 2014; Chuang, Church, \& Hu, 2016; Githens \& Aragon, 2009; McFadden \& Crowley-Henry, 2017). Tais ativistas tendem a concentrar-se na mobilização de empregados e a advogar em causas próprias, atentos às questões relacionadas a riscos e benefícios (Briscoe et al., 2014; Chuang et al., 2016). Desse modo, o ativismo interno comumente evita conflitos abertos, buscando uma atuação consensual, sem descuidar das relações de poder (Olsson \& Hysing, 2012). Já o ativismo externo, atuando em campos organizacionais, inclusive internacionais, mobiliza recursos para moldar ambientes institucionais, utilizando-se de táticas para ganhar cobertura da mídia e influenciar tomadores de decisões (Briscoe et al., 2014; Olsson \& Hysing, 2012).

A pesquisa sobre LGBT em organizações, de modo amplo, internacionalmente e nacionalmente, não tem se desenvolvido no mesmo compasso que outras dimensões da diversidade, como raça e deficiência (Freitas, 2015; Köllen, 2016; Ng \& Rumens, 2017). Identificou-se a partir de artigos e revisões de literatura recentes que as questões predominantes desse campo envolvem a discriminação contra a população LGBT e as medidas e políticas adotadas pelas organizações para esses grupos (McFadden \& Crowley-Henry, 2017; Paniza, 2020; Pompeu \& Souza, 2018; Schmidt, Githens, Rocco, \& Kormanik, 2012).

Ainda nesse cenário da pesquisa sobre LGBT nas organizações, é importante acrescentar que o campo no Brasil tem avançado e se articulado em diversas perspectivas, como identidade e cultura gay (Silva, Bastos, Lima, Ferraz, \& Cabral, 2013; \& Zauli-Fellows, 2006); violência moral e discriminação no trabalho (Garcia \& Souza, 2010; et al., 2009); políticas de diversidade (Saraiva \& Irigaray, 2009; Souza et al., 2012; Diniz et al., 2013); efeitos de ser LGBT nas organizações (Irigaray \& Freitas, 2011); implicações socioprofissionais da decisão de permanecer ou sair do armário (Caproni Neto, Saraiva, \& Bicalho, 2014; Gomes \& Felix, 2019; Rabelo \& Nunes, 2017); estratégias de sobrevivência no ambiente de trabalho (Irigaray \& Freitas, 2013); heteronormatividade, feminilidade e questão queer (Souza \& Carrieri, 2010; Souza, 2017; Moura \& Nascimento, 2020); e a estigmatização de transexuais e travestis (Baggio, 2017; Carrieri, Souza, \& Aguiar, 2014).

Assim, demonstra-se que, apesar do amplo interesse no tema, emerge a necessidade de ampliar no País a discussão específica sobre ativismo, de forma mais avançada internacionalmente. Em âmbito nacional, foi localizado apenas um capítulo de livro que trata desse tema no Brasil (\& Andrade, 2012). Os autores relatam a experiência de um empregado e ativista gay que auxiliou na sistematização de ações para o combate à discriminação e valorização da diversidade sexual e de gênero no trabalho, tais como 
elaboração de carta de princípios de respeito à diversidade e a realização de treinamentos e discussões para sensibilização e educação acerca do tema em uma instituição (Siqueira \& Andrade, 2012).

Essa constatação acaba por estimular a seguinte questão de pesquisa: "qual tem sido o debate acadêmico em relação ao ativismo LGBT nas organizações?" Diante dessa conjuntura, o objetivo do artigo é o de fazer uma análise bibliográfica, fundamentadanabase Scopus, daárea deadministração e ciências sociais, no período de 2010 a 2019, acerca do debate internacional sobre o tema ativismo LGBT no ambiente organizacional. Para tal, realizou-se uma análise do panorama dessa pesquisa, teoria, metodologia utilizada e contribuições, de modo a propor uma agenda de pesquisa nacional, cuja abordagempossibiliteaemergência denovas investigações. Noplanoteóricoconceitual, este estudo contribui com uma revisão atualizada da literatura internacional, sinalizando para os aspectos e dinâmicas do ativismo LGBT em organizações que vêm sendo estudadas e reconhecendo, inclusive, a emergência de novas discussões. No plano metodológico, o estudo reúne o conjunto das principais publicações recentes no campo sob suporte do protocolo da pesquisa de revisão sistemática da literatura de Cronin, Ryan e Coughlan (2008). À vista disso, esse artigo preenche uma lacuna dos estudos nacionais do campo dos estudos organizacionais, ampliando a discussão do tema LGBT pela discussão de movimentos políticos internos à organização que podem inspirar outros grupos a estabelecerem lutas semelhantes, além de auxiliar no processo de transformação social, considerando-se a influência na formulação de políticas (Olsson \& Hysing, 2012) que promovem maior legitimidade democrática de igualdade de direitos e respeito às diferenças.

O trabalho encontra-se assim estruturado: após esta introdução, apresenta-se a contextualização da emergência do ativismo LGBT nas organizações. Em seguida, descreve-se o procedimento metodológico que pautou a revisão sistemática de literatura. Na sequência, os resultados e as discussões são abordados, contemplando uma agenda atualizada de pesquisa. Por fim, as considerações finais apontam conclusões e sugestões deste estudo.

\section{Emergência do Ativismo LGBT nas Organizações}

No que tange ao preconceito, os sujeitos nas organizações vivenciam, como no contexto social, os mesmos estigmas contra grupos minoritários considerados marginalizados. No caso dos empregados LGBT, tal preconceito manifesta-se a partir de atos discriminatórios: é a injúria sob o manto do bom humor (Irigaray, Saraiva, \& Carrieri, 2010; Pompeu \& Souza; 2019; Saraiva \& Irigaray, 2009), mas é também a exclusão, o ostracismo e o assédio moral cotidianos, vivenciados ora velada, ora explicitamente, deixando suas marcas simbólicas (Carrieri et al., 2014; Moura \& Nascimento, 2020; Siqueira et al., 2009), e que afeta, inclusive, a maneira com que empregados LGBT vivenciam suas identidades no trabalho (Caproni Neto et al., 2014; Gomes \& Felix, 2019; Irigaray \& Freitas, 2011). 
Tal discriminação reflete-se noutras questões específicas da ordem organizacional, promovendo consequências em termos de convivência e atravancando direitos e benefícios concernentes aos LGBT. Barreiras são impostas na contratação e obstáculos colocados para a ascensão na carreira (Aksoy, Carpenter, Frank, \& Huffman, 2018; Carrieri et al., 2014; McFadden, 2015), mostrando o LGBT, como inapto à liderança, por exemplo (Barrantes \& Eaton, 2018). Em inúmeras empresas, não se dispõe de benefícios, tais como planos de saúde e previdenciário estendidos aos parceiros. Assim, tendo em vista que atos discriminatórios moldam e definem a relação entre indivíduo LGBT e organização, e que persiste o clima heterossexista no local de trabalho - cuja ação promove a discriminação em estruturas organizacionais em que a heterossexualidade continua a ser a norma -, uma saída pode ser o ativismo LGBT. Principalmente porque, como constatado por Diniz et al. (2013), Saraiva e Irigaray (2009) e Souza et al. (2012), as políticas de diversidade podem funcionar mais como princípios do que como práticas socialmente comprometidas.

Dessa forma, para lidar com discriminação do empregado LGBT nas organizações, outros atores, que não sejam os próprios gestores, podem emergir buscando direitos e benefícios (Githens \& Aragon, 2009). Assim, grupos ativistas corporativos LGBT estimulam cada vez mais as empresas a abordarem questões de diversidade, buscando influenciar a natureza e o nível das atividades corporativas de mudança social (Siqueira \& Andrade, 2012). Essas ações reverberam não só na concessão de benefícios e medidas concretas, como a inclusão do parceiro do mesmo sexo no plano de saúde para empregados gays e lésbicas, mas também no fomento a grupos de afinidade LGBT, de modo a subsidiar "a revisão de políticas, programas e processos de gestão de pessoas e responsabilidade social" (Siqueira \& Andrade, 2012, p. 112).

Ao se visitar a literatura internacional, depreende-se que o ativismo LGBT é algo mais amplo, visto que também há "[...] grupos que existem sem o reconhecimento do empregador, seja porque eles são informais e não estruturados, ou porque seus objetivos são incompatíveis com os objetivos do empregador" (Githens \& Aragon, 2009, p. 124, tradução nossa). Ou seja, indivíduos LGBT podem criar grupos ativistas juntando-se em redes vagamente organizadas (Diani \& McAdam, 2003) ou, dependendo da sua capacidade para mobilizar recursos, criar grupos ativistas socialmente formais (Den Hond \& De Bakker, 2007). Nesse sentido, Githens e Aragon (2009) propuseram quatro abordagens para o reconhecimento de grupos ou redes LGBT e suas práticas de ativismo associadas às organizações, desmembrando-as em internas ("convencional" e "informal internamente responsiva") e externas ("não oficial organizada" e "radical/queer").

Em âmbito interno, na "abordagem convencional", grupos de recursos de empregados e comitês de diversidade figuram como principais exemplos de ativismo. Esses grupos são formalmente sancionados pela organização, a qual institui programas formais e encoraja discussões sobre diversidade para benefício da organização como um todo. O objetivo é enfatizar a efetividade organizacional e o esforço dá-se reativamente (Githens \& Aragon, 2009). Já a "abordagem informal internamente responsiva" compreende grupos de redes e grupos de mentoria informais. Nessa abordagem, os grupos não são 
estruturados oficialmente, mas se dedicam a questões como desenvolvimento de carreira e apoio social mútuo entre os próprios trabalhadores LGBT. Incentivam a diversidade para obter vantagem competitiva, de modo que a pressão por efetividade organizacional advém dos grupos de LGBT informais que emergem no seio da organização (Githens \& Aragon, 2009).

No campo externo à organização, os autores indicaram que a "abordagem não oficial organizada" exemplifica-se por meio de grupos sindicais LGBT, que dispõem sobre o combate à discriminação LGBT. Esses grupos são estruturados externamente e não sancionados pela organização empregadora. Seu objetivo é conjugar mudança na sociedade com mudança organizacional, e seu esforço também se dá reativamente, o que significa uma ação dependente de exigência anterior (Githens \& Aragon, 2009). Quanto às "abordagens radicais/queer", a forma que se tem é a de grupos sociais informais e movimentos que clamam por mudanças subversivas. A estrutura, não formal, permite advogar por mudanças explícitas que atendam o objetivo de rejeitar a concepção binária gay/hétero, por exemplo, trabalhando com amplas coalizões e integrando questões sociais mais amplas ao ativismo queer. Esses grupos têm sua atuação emergente (Githens \& Aragon, 2009).

Nesse sentido, o ativismo dos empregados é exemplo poderoso que emerge do cruzamento de organizações de trabalho e movimentos sociais (Raeburn, 2004). Para entender o ativismo nas corporações, pesquisadores como King e Pearce (2010) e Schneiberg e Lounsbury (2008) adotaram a ideia de "estrutura de oportunidade", premissa na qual as condições contextuais é que dão forma à probabilidade de o ativismo ser bem-sucedido. Para Briscoe et al. (2014), os valores pessoais dos dirigentes de empresa constituem-se em um dos elementos-chave da estrutura de oportunidade para os ativistas. Sendo assim, muitos empregados que contemplam o ativismo LGBT estarão atentos às inclinações ideológicas de seus dirigentes, prontos a mitigar represálias e assédio de supervisores e colegas, já que estes podem reagir negativamente por suas ideologias pessoais ou por seus conflitos frente à convivência com homossexuais (Ragins \& Cornwell, 2001; Scully, Creed, \& Ventresca, 1998).

Assim, se por um lado, ativistas internos, muitas vezes, possuem informações sobre as coalizões e os canais de influência necessários para lobby efetivo e podem ter conexões com gerentes seniores que poderiam ajudá-los (Soule, 2012), também pode ser que estes mesmos empregados ativistas dependentes de seus empregadores não sejam suscetíveis de usar estratégia de confronto que envolva retenção de recursos como greve ou boicote. Salienta-se então que outras partes interessadas, como parceiros de negócio ou reguladores, possibilitam desfrutar de um conjunto mais amplo de influência e opções de manifestar-se (Frooman, 1999; Soule, 2012).

Por isso, os movimentos sociais reconhecem que são os indivíduos que devem agir, mas que essa adesão é bastante influenciada pelos riscos pessoais de sua participação, o que implica a importância dos aspectos individuais - ideologia/experiências anteriores - e de estrutura - para apoiar nessa decisão (McAdam, 1986; Schussman \& Soule, 2005). Os atores que decidem agir respondem a consequências que vão da rejeição hostil à aquiescência e/ou a endosso entusiasmado, pois, na esfera corporativa, essas respostas não são geradas por "organizações" amorfas, mas emanam 
de debates e deliberações no dia a dia (Briscoe et al., 2014). Portanto, esses agentes de mudança moldam e capitalizam oportunidades na política interna de uma organização, formando grupos internos de empregados LGBT (Githens \& Aragon, 2009; Schmidt et al., 2012) para desafiar e reformar culturas (Creed \& Scully, 2000).

\section{- Procedimento Metodológico}

No que compete ao universo das questões que associam LGBT e organizações foi possível constatar que revisões de literatura anteriores (a partir de 2014) (Anteby \& Anderson, 2014; Martinez et al., 2017; Ng \& Rumens, 2017; Paniza, 2020; Pompeu \& Souza, 2018; Webster, Adams, Maranto, Sawyer, \& Thoroughgood, 2017) não têm adotado protocolos de revisão sistemática. A importância dessa constatação reside em permitir explorar caminhos metodológicos alternativos para a literatura que tradicionalmente envolve LGBT nas relações de trabalho e, sobretudo, no ativismo.

A partir disso, este estudo adotou o protocolo de revisão sistemática da literatura de Cronin et al. (2008). A escolha pautou-se na ampla aplicabilidade do protocolo a várias áreas do conhecimento e no seu rigor metodológico em comparação às tradicionais revisões (Cronin et al., 2008). De acordo com Cronin et al. (2008), o passo a passo obedece a critérios e procedimentos, os quais agrupam-se em cinco etapas: i) definição da questão de pesquisa; ii) definição dos critérios de inclusão/exclusão; iii) acesso à literatura; iv) avaliação da qualidade da literatura incluída; v) análise, síntese e disseminação dos resultados. Considerando a questão "qual tem sido o debate acadêmico em relação ao ativismo LGBT nas organizações?", subsequentemente, duas decisões relacionadas aos critérios de inclusão e exclusão foram tomadas.

A primeira compreendeu a definição dos descritores de busca em três dimensões: i) relativos aos indivíduos LGBT ("lesbians", "gays", "bisexuals", "transexuals"), ou a sigla "LGBT"; ii) relativos à organização e ao trabalho ("workplace", "employee"); e iii) relacionados ao ativismo LGBT (interno e externo) nas organizações ("workplace activism", "employee activism"), baseiam-se em palavras-chave específicas para designar ativismo ("employee resource groups", "employee networks", "affinity groups") (Githens \& Aragon, 2009). Para formar uma sintaxe de busca, descritores foram conjugados entre si, perfazendo diferentes permutações (Tabela 1). Tal estratégia visa atender o que McFadden (2015) chama de "cadeia de pesquisa", adequada para buscas específicas, como é o caso do LGBT nas organizações, que deve trazer descritores associados: i) ao contexto (organizações, trabalho) e; ii) à população (lésbicas, gays, bissexuais, transexuais etc.). Dessa forma, nesta pesquisa, surge uma terceira parte dessa cadeia, a qual indica descritores correspondentes ao ativismo (Tabela 1).

A segunda decisão concerne à base de dados adotada. Optou-se pela busca na base de dados Scopus, devido ao seu reconhecimento pela interdisciplinaridade e elevada quantidade de materiais internacionais em ciências humanas e sociais, que oferecem visão geral da pesquisa mundial com rigoroso critério de seleção dos títulos, os quais devem atender a 
critérios como qualidade, revisão por pares, possuir ISSN e respeito a aspectos éticos. A Scopus abarca uma vasta base de periódicos obtidos de importantes editores internacionais como: Cambridge University Press; Elsevier; Springer; American Association for the Advancement of Science (Science); BMJ Publishing Group; American Psychological Association (APA); Taylor \& Francis e outros (Larsen \& Rathemacher, 2017; Scopus, 2020). Acrescenta-se que um pré-teste foi realizado nas bases Science Direct e Web of Science, mas os resultados foram reduzidos, de maneira que se utilizou apenas a base supramencionada.

Com base em tais critérios, iniciaram-se as buscas, o que corresponde à etapa de acesso à literatura (Cronin et al., 2008). No campo de pesquisa, foram adotadas as combinações de descritores mencionadas, culminando em 11 buscas e seus respectivos resultados (Tabela 1). Nas buscas na plataforma, os filtros marcados foram: i) área de conhecimento: administração e ciências sociais; ii) período: de 2010 a 2019; iii) tipo do material: apenas artigos (teóricos e teórico-empíricos), mitigando outras revisões da literatura; iv) campos para varredura: "título", "resumo" e "palavras-chave". Efetuada a seleção dos artigos, procedeu-se à avaliação da qualidade da literatura, que indica a filtragem de somente estudos que atendam à questão de pesquisa colocada (debate sobre ativismo LGBT em organizações) e aos critérios técnicos delimitados (descritores, base de dados, área de conhecimento, tipo de material e campo para varredura). As buscas retornaram, em termos brutos, 61 artigos no total. Eliminados estudos em duplicidade (que retornaram mais que uma vez ao longo das 11 buscas, necessitando descarte), restaram 40 estudos. Na sequência, uma análise aprofundada de abstracts - levando em conta a questão da pesquisa definida no primeiro passo - possibilitou descartar mais 24 artigos, remanescendo, para análise final, 16 publicações (Tabela 1).

Tabela 1: Resumo das etapas de acesso à literatura e avaliação de qualidade

\begin{tabular}{clc}
\hline Busca & \multicolumn{1}{c}{ Descritores empregados } & Retorno \\
\hline 1 & Gay OR Lesbian OR Bissexual OR Transgender AND 'Activis*' AND 'employee' & 6 \\
2 & Gay OR Lesbian OR Bissexual OR Transgender AND 'Activis*' AND 'workplace' & 8 \\
3 & Gay OR Lesbian OR Bissexual OR Transgender AND 'Affinity group' & 5 \\
4 & Gay OR Lesbian OR Bissexual OR Transgender AND 'Employee Networks' & 1 \\
5 & Gay OR Lesbian OR Bissexual OR Transgender AND 'Employee Resource Group' & 3 \\
6 & LGBT affinity groups & 4 \\
7 & LGBT employee activism & 4 \\
8 & LGBT employee networks & 4 \\
9 & LGBT employee resource groups & 3 \\
10 & LGBT organizations activis* & 20 \\
11 & LGBT workplace activis` & 3 \\
& Total bruto & 61 \\
& Total após remoção de duplicatas & 40 \\
& Total após leitura de abstracts (aptos para análise final) & 16 \\
\hline
\end{tabular}

Nota: Legenda para operadores booleanos empregados: "AND": interseção entre os termos; "OR": para mais de um sujeito da sigla LGBT; "*”: para alcançar palavras com diferentes terminações em um mesmo radical. 
Por fim, na etapa de análise, síntese e disseminação dos resultados (Cronin et al., 2008), foi analisado o conjunto final de artigos levantados, tendo como parâmetro três dimensões congruentes ao objetivo desta pesquisa:

i. Panorama da produção científica internacional: análise dos principais indicadores associados às publicações, sendo eles: periódico, fator de impacto do periódico, número de citações, autores e ano das publicações; acrescentados de uma análise acerca dos principais sujeitos de pesquisa dentro do acrônimo LGBT;

ii. Contribuições dos artigos analisados e estruturas/objetivos do ativismo LGBT em organizações: análise do quesito empírico, em que, partindo das abordagens sobre grupos LGBT em organizações, de Githens e Aragon (2009), busca-se classificar os achados em "abordagem convencional", "abordagem informal internamente responsiva", "abordagem não oficial organizada", e "abordagem radical/queer";

iii. Aspectos teóricos-metodológicos: análise centrada nos principais conceitos e perspectivas empregadas pelos autores, bem como sobre as características envolvendo delineamentos de pesquisa mais comuns.

Por fim, é proposta uma agenda de pesquisa nacional acerca do ativismo LGBT, a partir das três dimensões anteriores, seja com sugestões para pesquisas futuras advindas dos próprios artigos, ou mesmo com reflexões tecidas pelos autores deste escrito.

\section{Resultados e Discussão}

\section{Panorama da Produção Científica Internacional}

Para analisar que debates têm perpassado, nos últimos dez anos, os estudos sobre ativismo LGBT no cenário organizacional, caracterizou-se a produção científica internacional sobre o tema (Tabela 2). Na sequência, retrata-se a relevância do tema sob diferentes ângulos, descrevendo os seguintes aspectos quantitativos deste conjunto de publicações: recorrência de autores; ano de publicação; recorrência de periódicos; fator de impacto dos periódicos; número de citações; e qual população do grupo LGBT tem sido objeto de estudo mais recorrente. 
Tabela 2: Relação de artigos selecionados para análise

\begin{tabular}{|c|c|c|c|}
\hline Autores e Ano de Publicação & Periódico e Fator de Impacto (Fi) & $\mathrm{N}^{0}$ citações & População \\
\hline $\begin{array}{l}\text { Brewster, Velez, Mennicke e Tebbe } \\
\text { (2014) }\end{array}$ & $\begin{array}{l}\text { Psychology of Sexual Orientation and Gender } \\
\text { Diversity }\left(^{\star}\right)\end{array}$ & 84 & Transgêneros \\
\hline Colgan e McKearney (2012) & Equality, Diversity and Inclusion (*) & 63 & Lésbicas, gays e bissexuais \\
\hline Everly e Schwarz (2014) & Human Resource Management (2.843) & 45 & LGBT \\
\hline $\begin{array}{l}\text { Holland, Rabelo, Gustafson, } \\
\text { Seabrook e Cortina (2016) }\end{array}$ & Psychology of Men \& Masculinity (1.926) & 45 & Gays e bissexuais \\
\hline Köllen (2016) & $\begin{array}{l}\text { The International Journal of Human Resource } \\
\text { Management (3.150) }\end{array}$ & 25 & Gays e lésbicas \\
\hline Drezner e Garvey (2016) & Frontiers in Psychology (3.201) & 22 & LGBTQ \\
\hline Woodruffe-Burton e Bairstow (2013) & Gender in Management (1.206) & 19 & Lésbicas \\
\hline Rhodes (2017) & Gender, Work \& Organization (2.273) & 13 & ** \\
\hline Githens (2012) & Human Resource Development Quarterly (3.000) & 10 & LGBTQ \\
\hline McFadden e Crowley-Henry (2017) & $\begin{array}{l}\text { International Journal of Human Resource Management } \\
\text { (3.150) }\end{array}$ & 10 & LGBQ \\
\hline Willis (2010) & Journal of LGBT Youth (*) & 9 & LGBQ \\
\hline $\begin{array}{l}\text { McNulty, McPhail, Inversi, Dundon e } \\
\text { Nechanska (2017) }\end{array}$ & $\begin{array}{l}\text { International Journal of Human Resource Management } \\
\text { (3.150) }\end{array}$ & 9 & Lésbicas, gays e bissexuais \\
\hline Chuang, Church e Hu (2016) & Journal of Management (9.056) & 8 & LGBT \\
\hline Murphy (2012) & Radical History Review (*) & 5 & ** \\
\hline Chan (2018) & Sexuality \& Culture $\left(^{*}\right)$ & 3 & ** \\
\hline $\begin{array}{l}\text { Rengers, Heyse, Otten e Wittek } \\
\text { (2019) }\end{array}$ & Nonprofit and Voluntary Sector Quarterly (1.925) & 2 & Lésbicas e gays \\
\hline
\end{tabular}

Nota: a) Fatores de impacto consultados com base no índice InCites (2018); b) Número de citações consultados com base no Google Scholar; c) (*): Periódicos que não integram o índice InCites (2018); d) **: Estudo em que a população não foi acessada devido ao delineamento teórico.

A Tabela 2 indica que, à exceção do International Journal of Human Resource Management, a divulgação de estudos sobre o ativismo LGBT em organizações não foi recorrente em mais de um periódico. Compreende-se, assim, que a publicação sobre o tema tem ocorrido em uma gama de periódicos, em três domínios principais: i) estudos organizacionais, administração e recursos humanos (Chuang et al., 2016; Everly \& Schwarz, 2014; Githens, 2012; Köllen, 2016; McFadden \& Crowley-Henry, 2018; McNulty, McPhail, Inversi, Dundon, \& Nechanska, 2017); ii) sexualidade, orientação sexual e questões de gênero em geral (Brewster, Velez, Mennicke, \& Tebbe, 2014; Chan, 2018; Holland, Rabelo, Gustafson, Seabrook, \& Cortina, 2016; Willis, 2010); e iii) interseção entre os dois domínios anteriores (Colgan \& McKearney, 2012; Rhodes, 2017; Woodruffe-Burton \& Bairstow, 2013). 
Ao considerar os Fatores de Impacto (Fi) dos periódicos, a Tabela 2 aponta somente um estudo publicado em periódico com Fi elevado (Chuang et al., 2016). Os demais encontram-se publicados ou em periódicos com Fi moderado (entre 1.206 e 3.150) (Drezner \& Garvey, 2016; Everly \& Schwarz, 2014; Githens, 2012; Holland et al., 2016; Köllen, 2016; McFadden \& Crowley-Henry, 2018; McNulty et al., 2017; Rengers, Heyse, Otten, \& Wittek, 2019; Rhodes, 2017; Woodruffe-Burton \& Bairstow, 2013) ou em periódicos sem Fi (Brewster et al., 2014; Chan, 2018; Colgan \& McKearney, 2012; Murphy, 2012; Willis, 2010). Assim, pode-se inferir que a pesquisa tem se restringido a periódicos de baixo alcance internacional. Para o caso dos periódicos sem fator de impacto, isso pode indicar estudos com impacto apenas localizado.

Por outro lado, alguns desses estudos vinculados a periódicos de baixo fator de impacto - ou até sem fator de impacto, como é o caso de Brewster et al. (2014), Colgan e McKearney (2012) e Woodruffe-Burton e Bairstow (2013), por exemplo -, têm expressivo número de citações. No entanto, no quadro geral, os artigos contam, em sua maioria, com menos de dez citações, sejam eles mais antigos (e.g.: Githens, 2012; Murphy, 2012; Willis, 2010) ou mais recentes (e.g.: Chuang et al., 2016; McNulty et al., 2017; McFadden \& Crowley-Henry, 2018). Observa-se também que, quanto à distribuição das publicações ao longo do período, ao menos uma publicação ao ano sobre a temática ocorreu. No que compete aos principais investigadores do campo, não foi possível estabelecer nesse grupo nenhum autor recorrente.

Em relação aos sujeitos do acrônimo LGBT contemplados nas pesquisas, nota-se, a partir do conjunto das publicações coletadas que os estudos sobre ativismo LGBT relacionado ao ambiente organizacional incluem em sua maioria a população gay, o que confirma o achado nacional de Paniza (2020), quando observa que a pesquisa sobre LGBT no Brasil privilegia a abordagem seja sobre o empregado gay, seja sobre o consumidor gay. Observa-se, na presente revisão, que publicações como as de Colgan e McKearney (2012), Holland et al. (2016), McFadden e Crowley-Henry (2017), McNulty et al. (2017) e Willis (2010) evidenciam que, quando não se deixa de incluir o restante das identidades da sigla, estes outros quando são incluídos são, por exemplo, entrevistados em menor número quando comparados aos homens gays. Isto indica um descompasso que é transversal ao tópico que intersecciona LGBT e organizações ou ambiente de trabalho, refletindo-se inclusive em temas emergentes, como é o caso do ativismo desses empregados.

Nesse sentido, é possível fazer um paralelo desses achados com as três metáforas evidenciadas por Paniza (2020) para caracterizar as pesquisas envolvendo indivíduos LGBT e organizações, a saber: emergência; submersão; e silêncio. A população transgênero encontra-se em silêncio dentro do ativismo LGBT, visto a constatação de apenas um estudo inserindo esse público de modo específico (Brewster et al., 2014). Em muitos dos casos o que observou-se foi apenas a menção ao "T" perdido dentro da sigla, assim como o "Q", que apesar da emergência dentro dos rótulos da Tabela 1, careceu de maiores aprofundamentos sobre quem seriam tais sujeitos, especialmente quando se considera estudos como os de Githens (2012), Willis (2012) e McNulty et al. (2017). 
Rememora-se que queer pode abranger posições identitárias fora dos binarismos mulher/homem e/ou homossexual/heterossexual, bem como, ser alternativa à sigla LGBT, de modo que signifique orientações não-heterossexuais (McFadden, 2015). Contudo, em âmbito da pesquisa, queer é uma categoria identitária, próxima à expressão genderqueer - para dialogar com as multidões queer. Para Preciado (2011), o termo não se restringe a um "terceiro sexo" ou um "para além dos gêneros". Fala-se de múltiplas dissidências de gênero, que podem referir-se a si como homem e mulher, nem homem e nem mulher, "genderfluid (movendo-se entre os gêneros) [...]" (McFadden, 2015, p. 148, tradução nossa). É uma postura de corpos que se levantam contra tudo aquilo que os construam como "normais" ou "anormais" (Preciado, 2011).

Quanto à população lésbica, admite-se a metáfora da submersão, cuja sub representatividade é dupla: "porque além da orientação sexual, também se dá por serem mulheres" (Paniza, 2020, p. 25). Nesse sentido, tal população também aparece apenas uma vez no escopo de estudo envolvendo ativismo LGBT organizacional (Woodruffe-Burton \& Bairstow, 2013), mas, diferentemente de T ou Q, o L vem acompanhado do G, cuja metáfora, evidentemente, é a da emergência, sendo ainda a categoria predominante nesses estudos. Em relação à população bissexual, pode ser caracterizada entre submersão e emergência, já que, se, por um lado, são encontrados em grande parcela nos estudos analisados, não há artigo dedicado especificamente à compreensão das vivências e enfrentamentos de bissexuais em organizações.

Portanto, é possível indicar que a pesquisa envolvendo os diferentes meios de se fazer ativismo LGBT no cenário organizacional ainda representa um impulso nascente, e que nasce com o mesmo desafio de contemplar outros sujeitos para além da hegemonia da identidade gay, conforme já fora destacado por outros estudos do tipo revisão de literatura que interligaram as questões dos LGBT em organizações (McFadden, 2015; Ng \& Rumens, 2017; Pompeu \& Souza, 2018; Webster et al., 2017). É um campo de pesquisa provavelmente periférico, se for feita uma análise ponderando o fato de os estudos se restringirem a periódicos de baixo fator de impacto internacional. Todavia, é também um campo que sinaliza emergência, já que a maior parcela de periódicos é ligada ao domínio dos estudos organizacionais e que ao menos uma publicação ocorreu por ano no decorrer da década.

\section{Contribuições dos artigos analisados e estruturas e objetivos do ativismo LGBT em organizações}

O propósito dessa subseção é o de retomar a classificação proposta por Githens e Aragon (2009), de modo a compreender o ativismo LGBT nos estudos teórico-empíricos analisados. A partir da identificação tanto dos objetivos de tais grupos (se eram alinhados à efetividade organizacional ou à mudança social) bem como da estrutura adotada (se institucional/formal ou emergente/informal), foi possível classificar a maioria dos estudos como congruentes ao quadrante da "abordagem informal internamente responsiva" (Tabela 3). Ou seja, tratam-se, em sua maioria, de grupos que, estruturados informalmente em um contexto institucional maior de uma organização, possuíam seus objetivos alinhados à efetividade organizacional (Githens \& 
Aragon, 2009). Discute-se então, na sequência, à luz das quatro abordagens propostas por Githens e Aragon (2009), não apenas objetivos e estruturas do ativismo LGBT nas publicações, mas também, numa dimensão empírica, as contribuições e os benefícios apontados. Clarifica-se que a classificação prezou por não impor uma categorização mutuamente excludente, visto que alguns artigos poderiam ser mais bem compreendidos em mais de uma abordagem, tais como Colgan e McKearney (2012), Chuang et al. (2016), Githens (2012) e Holland et al. (2016).

No quadrante da "abordagem convencional" encontram-se estudos que atribuem aos grupos de afinidade e redes de recursos de empregados o papel de visibilidade alinhada à institucionalização, isto é, "grupos que tipicamente enfatizam sua conexão com os objetivos de seus empregadores por meio do discurso em torno da diversidade, do multiculturalismo e da satisfação dos funcionários (Githens \& Aragon, 2009, p. 127, tradução nossa). No que diz respeito à estrutura dos ativismos em organizações, esse processo se configurou pelo incentivo da própria organização à formação de redes internas LGBT, as quais são oficialmente reconhecidas e apoiadas pela gestão com recursos e visibilidade (Everly \& Schwarz, 2014; Köllen, 2016). O estudo de Everly e Schwarz (2014) evidenciou somente os grupos de recursos de empregados (Employee Resource Groups - ERGs) como desdobramento das políticas de diversidade das maiores organizações norte-americanas listadas na Fortune 1000, ao passo que o artigo de Köllen (2016) abordou a estrutura interna formal de ativismo LGBT em duas instituições financeiras alemãs, corroborando a "abordagem convencional" ao mencionar que os grupos tinham metas de não só visibilizar os empregados LGBT por meio de redes de empregados (Employee Networks), mas ainda eram encarregados de promover positivamente as instituições como empregadores aliados à população LGBT, dispondo inclusive de orçamento para isso (Köllen, 2016). Dessa forma, na "abordagem convencional", a rede pode ser parte da estrutura organizacional e seus objetivos estão alinhados ao da organização.

Tabela 3: Classificação dos achados segundo as abordagens de grupos LGBT em organizações

\begin{tabular}{|c|c|c|c|}
\hline \multirow{14}{*}{ 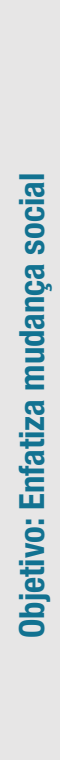 } & Estrutur & ente/informal & \multirow{15}{*}{ 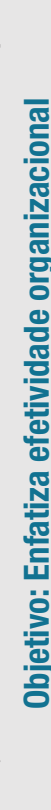 } \\
\hline & Abordagens radicais/queer & Abordagem informal internamente responsiva & \\
\hline & & Brewster et al. (2014) & \\
\hline & Chuang et al. (2016) & Woodruffe-Burton e Bairstow (2013) & \\
\hline & Githens (2012) & Drezner e Garvey (2016) & \\
\hline & Willis (2010) & Rengers et. al (2019) & \\
\hline & Chan (2018) & McFadden e Crowley-Henry (2017) & \\
\hline & & McNulty et al. (2017) & \\
\hline & Abordagens não oficiais organizadas & Abordagem convencional & \\
\hline & Churng ot al (2016) & Colgan e McKearney (2012) & \\
\hline & 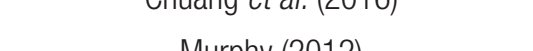 & Everly e Schwarz (2014) & \\
\hline & Hollond 0 & Githens (2012) & \\
\hline & 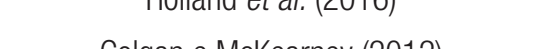 & Holland et al. (2016) & \\
\hline & ney & Köllen (2016) & \\
\hline \multicolumn{3}{|c|}{ Estrutura: Institucional/formal } & \\
\hline
\end{tabular}

Nota: Elaborado pelos autores com base em Githens e Aragon (2009). 
Sem deixar de enfatizar a efetividade organizacional, a "abordagem informal internamente responsiva" preza por grupos que operam, no interior da organização, não necessariamente pelo vínculo formal com a instituição, uma vez que são grupos que certamente não precisam do reconhecimento oficial e/ou tratam-se de encontros espontâneos entre colegas e aliados, formando-se organicamente em resposta às necessidades (Githens \& Aragon, 2009). É o caso do estudo de Brewster et al. (2014) que apontou a importância das interações colaborativas com transgêneros em transição de gênero no trabalho, bem como o de Woodruffe-Burton e Bairstow (2013), que sugerem relevância para redes informais no processo de gerenciamento e negociação da identidade sexual de lésbicas no ambiente de trabalho. Sublinha-se também o potencial da informalidade desses grupos em gerar voz e visibilidade no contexto de trabalho empresarial (McFadden \& Crowley-Henry, 2017), sobretudo no caso dos empregados expatriados em ambientes hostis às suas identidades (McNulty et al., 2017). Tratam-se de grupos que partem de uma perspectiva emergente, mas que não necessariamente buscariam evoluir para a formalização, uma vez que a informalidade os protege de estigmas (Drezner \& Garvey, 2016; Rengers et al., 2019). Além disso, as questões de desenvolvimento de carreira e apoio social são salientadas nessa abordagem (Githens \& Aragon, 2009).

No quadrante das "abordagens não oficiais organizadas", os grupos "se formam fora da organização empregadora para promover mudanças sociais nos locais de trabalho de seus membros [...] através de sindicatos ou outros grupos externos" (Githens \& Aragon, 2009, p. 130). Murphy (2012) atribui importância aos movimentos e sindicatos pró-LGBT fora das organizações como influenciadores de mudanças nas práticas organizacionais, inclusive na adoção de benefícios para homossexuais com parceiros não-casados no contexto de uma organização do setor aéreo.

Já nas "abordagens radicais/queer", a atuação é a mais subversiva. Nessa classificação estão compreendidos grupos que "existem no nível de base e adotam formas organizacionais emergentes com poucas fronteiras ou estruturas predeterminadas" (Githens \& Aragon, 2009, p. 131). Os objetivos sociais geralmente são mais amplos, como o enfrentamento do binarismo de gênero (Githens \& Aragon, 2009). Esses grupos buscam trabalhar para evitar todo tipo de exclusão por orientação sexual e identidade de gênero, seja por motivos sociais, políticos, econômicos ou de igualdade de direitos (Willis, 2010; Chan, 2018). Clarifica-se que uma proposta de ativismo LGBT consoante à perspectiva queer possibilita reunir os que desconstroem as classificações fixas de identidade em luta plural não circunscrita de antemão pela identidade, mas em movimento social de alianças que tenha por objetivo se opor às forças e aos regimes disciplinadores e reguladores que expõem vidas a condições precárias (Butler, 2018a), produzindo assujeitamentos e resistência (Foucault, 1995). Em Chan (2018), por exemplo, o ativismo era composto por grupos religiosos pró-LGBT, cujo esforço centrara-se em explicitar que a identidade sexual e de gênero dissidente não é diferente das majoritárias identidades heterossexuais e cisgêneras.

No caso dos estudos presentes em mais de um quadrante, observou-se um predomínio da interlocução entre a "abordagem convencional" e as demais. Colgan e McKearney (2012), em estudos com organizações dos 
setores público e privado e terceiro setor, indicara, em primeiro plano, as redes nos locais de trabalho como forma de proporcionar voz aos LGBT, papel discutido com ênfase em McNulty et al. (2017) e McFadden e Crowley-Henry (2017). Porém os autores não desconsideram o papel mediador que determinados grupos sindicais exercem nesse objetivo, abordando estas outras formas ativistas em segundo plano e sugerindo um alinhamento à "abordagem não-oficial organizada". Classificação similar é a de Holland et al. (2016), cuja discussão envolve as diferentes formas de ativismo no ambiente organizacional ou organizada de forma externa a este ambiente.

No segmento universitário, Githens (2012) tomou como objeto de análise duas organizações, sendo uma delas um grupo formal, alinhado à política de diversidade da cúpula da instituição. Esse grupo formou uma coalizão com grupos informais de modo a favorecer o desenvolvimento organizacional nas questões envolvendo LGBT em três campus universitários. O objetivo em questão era o de favorecer benefícios para parceiros de homossexuais não casados. O próprio autor sugere que a abordagem convencional é uma das utilizadas, o que fica evidente em um dos desdobramentos ser o de como a instituição poderia lidar com os ativistas não alinhados à premissa de efetividade organizacional, bem como de orientação e enfoque pela política queercomo meio para organização (Githens, 2012). É um caso de oscilação entre a "abordagem convencional" e a "abordagem radical/queer". Já Chuang et al. (2016), como abordaram diferentes organizações que são movimentos sociais, em maior ou menor grau de institucionalização, mas com objetivo de modificar uma prática social discriminatória por parte das organizações empregadoras da Fortune 500 entre 1990 e 2002 (a não concessão de benefícios de saúde para parceiros do mesmo sexo), é um estudo circunscrito na fronteira das "abordagens não oficiais organizadas" e "abordagem radical/queer", dado que não favorece o objetivo alinhado ao desempenho das organizações (Chuang et al., 2016).

Ainda no plano empírico, podem ser descritos como benefícios do ativismo LGBT, a partir de tais estudos: o de que empresas que têm grupos de afinidades possuem maiores possibilidades de adoção de benefícios de saúde para parceiros do mesmo sexo e reconhecimento das identidades LGBT (Chuang et al., 2016); a não ocultação da identidade LGBT pode favorecer o desempenho e o desenvolvimento (Woodruffe-Burton \& Bairstow, 2013); adquire importância nos processos de transição de gênero (Brewster et al., 2014); proporciona maior bem-estar psicológico, inclusive para aqueles não-LGBT (Holland et al., 2016); canais internos de comunicação e participação podem evitar o silenciamento, favorecendo a voz e a visibilidade para tal segmento (Colgan \& McKearney, 2012; McFadden \& Crowley-Henry; 2017; McNulty et al., 2017), de modo que ainda um clima organizacional mais inclusivo, que proporciona efetividade às políticas de diversidade (Everly \& Schwarz, 2014; Köllen, 2016).

Porém, a literatura permitiu recuperar contrapontos aos benefícios do ativismo LGBT. Um deles é o de que participantes desses grupos podem estar mais suscetíveis ao assédio, devido à visibilização em contextos altamente heteronormativos (Holland et al., 2013). Com base nos resultados de Willis (2010), também se entende que a identificação mútua entre LGBT não necessariamente favorece garantia contra o tratamento excludente, 
sugerindo que os colegas LGBT não são a única fonte de apoio e ainda podem atuar como perpetradores dos seus pares; o que desafia achados de estudos, como o de Rumens (2008), que defende a amizade entre LGBT como fonte de suporte a tais empregados. Inclusive nem todos os empregados LGBT buscarão ter voz e/ou visibilidade, conforme foi apontado em McFadden e Crowley-Henry (2017), devido ao receio de serem ainda mais estigmatizados como "bagunceiros". É uma questão que envolve o silêncio como um entrave ao ativismo LGBT, mas que suscita a análise de que essa seria na verdade uma estratégia para manter a identidade LGBT separada da profissional, pois conforme estudado por Irigaray e Freitas (2013), gays e lésbicas podem tomar posições identitárias que vão muito além do dicotômico in-closeted versus coming-out.

Nessa subseção, confirma-se a persuasão utilizada pelos empregados ativistas LGBT nas organizações (Briscoe et al., 2014), visto que a maior parcela foi oriunda da "abordagem informal internamente responsiva", a qual busca equilibrar as demandas das questões LGBT no trabalho com utilidade organizacional, fazendo, do ativismo, um instrumento informal. Tratam-se de grupos que sugerem um alinhamento à lógica do business case - expectativa de aumento de desempenho pela valorização da diversidade da força de trabalho (Oberfield, 2014) -, instrumentalizando a busca por justiça social pela condição de desempenho (Rhodes, 2017).

\section{Aspectos teórico-metodológicos}

Teoricamente, além dos conhecimentos tradicionalmente utilizados para investigar esses tipos de fenômenos relatados, como as teorias de gênero (Woodruffe-Burton \& Bairstow, 2013), assédio sexual (Holland et al., 2016), diversidade (Colgan \& McKearney, 2012) e estereótipos (McNulty et al., 2017), foi possível constatar a emergência de estudos organizacionais com perspectivas políticas (Chuang et al., 2016; Rhodes, 2017), confirmando sua importância nas mudanças organizacionais e seu alinhamento à discussão do ativismo.

Os estudos de Githens (2012), Everly e Schwarz (2014), McNulty et al. (2017), Chuang et al. (2016), Woodruffe-Burton e Bairstow (2013), Holland et al. (2016), Brewster et al. (2014) e Köllen (2016) examinaram efeitos de teorizações anteriores, isto é, tinham evidências empíricas associadas a fundamentos teórico-empíricos de estudos anteriormente realizados. No caso do ativismo discutido por Githens (2012), o sucesso das iniciativas pôde ser atribuído ao emprego tanto de grupos mais altamente estruturados quanto de coalizões unidas com outros atores externos. Em termos teóricos, ao utilizar-se do ativismo LGBT em função de busca por concessão igualitária de benefícios, o estudo contribui também para outra literatura - a de teoria do desenvolvimento organizacional -, interseccionando abordagens identitárias conjugadas às abordagens queer (Githens, 2012).

Nessa mesma linha, Everly e Schwarz (2014) sublinham que características demográficas dos decisores operam simultaneamente pressões externas (coercivas, miméticas e normativas), para influenciar a adoção de políticas favoráveis a LGBT. McNulty et al. (2017) identificam que estigmatização e 
discriminação podem afetar a voz do LGBT, reiterando a cultura do silêncio. Todavia, o estudo desses autores tem valor ao ressaltar as dimensões da voz LGBT na organização, quais sejam: profundidade, alcance e nível de oportunidades, sem desconsiderar os estereótipos negativos que pairam sobre redes de empregados. Essa discussão está relacionada ao ativismo LGBT no trabalho, quando se constata que esse movimento interno é impactado pela noção estereotipada que se tem de ativistas LGBT externos, o que pode promover auto discriminação e silenciamento (McNulty et al., 2017).

A questão da voz e do silêncio nas redes internas de LGBT problematiza o potencial da informalidade da comunicação, ao atender a demanda dos empregados das minorias sexuais e agregar valor à gestão, ao mesmo tempo em que recomenda maior inserção e desenho institucionalizado desses grupos, de modo a configurar estratégias inclusivas mais eficazes (McNulty et al., 2017). Uma base teórica comum aos dois artigos (McFadden \& Crowley-Henry, 2017; McNulty et al., 2017) foi o estudo de Dundon, Wilkinson, Marchington e Ackers (2004, p. 1149, tradução nossa), que examinou significados, propósitos e práticas da voz de empregados, concluindo que "o grau em que as práticas de voz estão incorporadas em uma organização é muito mais importante do que relatar a extensão de qualquer esquema individual ou coletivo específico para a voz dos empregados".

Köllen (2016) avaliou a interrelação entre clima organizacional percebido por empregados gays e lésbicas e a dimensão da orientação sexual no escopo de políticas de diversidade maiores no escopo de duas organizações de crédito, sugerindo um ativismo interno, guiado pela organização. Para tal, empregou um modelo teórico constituído à luz da perspectiva interacionista simbólica e de intersubjetividade. Esses conceitos, conjuntamente empregados, possibilitaram entender como certas iniciativas organizacionais terão maior impacto em determinados indivíduos do que em outros.

Com enfoque em redes de empregados LGBT, McFadden e Crowley-Henry (2018) abordaram a separação e o isolamento desses grupos dos demais LGBT em organizações, discutindo silenciamento de LGBT nas organizações. Para tal, privilegiaram conceitos centrados em características e propósitos dessas redes. No que concerne às redes internas de LGBT e dinâmica de voz/silêncio nas organizações, McNulty et al. (2017) tiveram enfoque similar ao de McFadden e Crowley-Henry (2018). A especificidade deles residiu em estudar LGBT expatriados e explorar a incapacidade desses empregados de se envolver em oportunidades de mobilidade global. Para tal, os autores valeram-se da teoria da ameaça dos estereótipos (Collins, 2007), que trata da amplitude de preconceitos a que indivíduos já estigmatizados estarão sujeitos dentro de determinadas estruturas institucionais. Nesse mesmo escopo de redes internas, Willis (2010) identificou o potencial de colegas queer mais velhos apoiarem trabalhadores LGBT mais jovens em empregos ou até se contrastar a estes. Seu estudo abordou no quadro teórico a sexualidade sob a perspectiva pós-estruturalista (Rubin, 1984), tecendo críticas às noções binárias de identidade e questionando a eficácia dos vínculos entre LGBT mais velhos e mais jovens.

Já Rengers et al. (2019), baseados na teoria fundamentada, que combina uma abordagem indutiva e dedutiva interativamente, construíram tipologia de três grupos para analisar como gays e lésbicas percebem sua 
inclusão no trabalho em relação ao dilema de divulgação e gerenciamento da sexualidade, ratificando a importância do contexto, como discutido por Briscoe et al. (2014), para a ação desses grupos. Drezner e Garvey (2016), que também trabalham indutiva e dedutivamente, sob epistemologia construtivista, utilizaram da teoria da motivação da justiça para sugerir o "Eu" como sendo motivo significativo para decisão de doar filantropicamente, e que o pertencimento a grupos de afinidades associados a percepção de clima organizacional acolhedor para essas minorias favorece o processo de doação de recursos por LGBT.

Nos ensaios teóricos de Murphy (2012) e Rhodes (2017), a discussão é teórico-crítica. O primeiro centraliza-se nas reivindicações políticas de famílias não tradicionais e LGBT como recursos no esforço de contestar o neoliberalismo (Murphy, 2012). O segundo problematiza o business case para entender a diversidade LGBT e reivindica um interesse genuíno para além da justificativa de ganhos de desempenho, ainda que esse possa criar oportunidades de justiça nas organizações (Rhodes, 2017). Colgan e McKearney (2012) salientam que, dicotomicamente, justiça social e diversidade dirigida por business case lhes parecem algo pouco útil de ser investigado, principalmente devido à falta de clareza ainda existente nessas abordagens. Tais estudos se relacionam com o ativismo LGBT no trabalho, na medida em que buscaram explorar gatilhos para o desenvolvimento de orientação política e prática de diversidade no setor privado (Colgan \& McKearney, 2012), assim como apresentam discussões que contestam o imperativo neoliberal (Murphy, 2012) e a noção instrumental de business case (Rhodes, 2017).

Brewster et al. (2014), ao examinarem experiências positivas e negativas de transgêneros no trabalho, recorreram à literatura sobre identidade de gênero e transição no local de trabalho. Githens (2012) utilizou a tipologia de grupos de ativismo LGBT nas organizações (Githens \& Aragon, 2009), conjugada ao modelo de desenvolvimento organizacional crítico de Bierema (2010) - este último visa à compreensão do contexto organizacional a partir da crítica e da reflexão que ensejam a ação de desenvolvimento, visando ao bem-estar geral de uma organização. Colgan e McKearney (2012) consideraram elementos estruturais, políticos e práticos da história da sexualidade no trabalho, como igualdade e diversidade, debatendo implicações da difusão de gestão da diversidade, com base no business case.

Essas discussões se alinham, como ficou evidente na maioria dos estudos, à natureza qualitativa, com exceções de Chuang et al. (2016), Everly e Schwarz (2014), Holland et al. (2016) e Köllen (2016), cujos trabalhos adotaram abordagem quantitativa e analisaram dados por covariância (o primeiro supracitado) e correlação (o segundo, o terceiro e o quarto artigos supracitados). Nas coletas de dados, ocorreu predominância da entrevista como instrumento, ainda que, em alguns casos, fossem utilizadas também a pesquisa documental e a observação. Foi constatada também a viabilidade da aplicação de ferramentas eletrônicas em estudos quantitativos (Everly \& Schwarz, 2014; Holland et al., 2016; Köllen, 2016) e qualitativos (Brewster et al., 2014; Woodruffe-Burton \& Bairstow, 2013). Nas análises dos dados, sobressaiu-se o uso de categorias temáticas, método interpretativo de dados e convergente aos estudos qualitativos (Brewster et al., 2014; Chan, 2018; Githens, 2012; McFadden \& Crowley-Henry; 2017; McNulty et al., 2017; Willis, 2010; Woodruffe-Burton \& Bairstow, 2013). 
Os artigos analisados também sugerem ampla adesão à abordagem interpretativista (Brewster et al., 2014; Chan, 2018; Colgan \& McKearney, 2012; Drezner \& Garvey, 2016; Githens, 2012; McFadden \& Crowley-Henry, 2017; McNulty et al., 2017; Rengers et. al, 2019; Heyse, Otten, \& Wittek, 2019; Willis, 2010; Woodruffe-Burton \& Bairstow, 2013), a qual reconhece uma multiplicidade de realidades possíveis de serem construídas. Embora o interpretativismo enfatize a subjetividade, contrapondo-se à ênfase objetivista e causal presente nos estudos funcionalistas, por outro lado, deixa de destacar a mudança radical, isto é, não tece críticas aos próprios arranjos sociais, sendo esses mesmos estudos fundamentados na lógica da ordem, a qual preza unidade e consenso. Por isso, o paradigma interpretativista não se afasta totalmente do funcionalismo, visto estar fundamentado na mesma visão de sociedade (Paula, 2016). Por exemplo: McNulty et al. (2017), embora compreendam subjetivamente as redes, propuseram a configuração prática desses ativismos internos para o formato institucionalizado de modo a ganhar em níveis de inclusão.

Ainda no grupo de estudos de abordagem interpretativista, Chan (2018), ao examinar a estrutura organizacional de grupos religiosos próLGBT, identificou como esses grupos lutam pela promoção da inclusão da diferença sexual e de gênero. O estudo advoga que a formação religiosa se constitui como espaço para acolhimento e frente de luta por respeito, afastando-se de concepções heteronormativas, que comumente são associadas ao grupo religioso. Além disso, propõe uma perspectiva alternativa para grupos ativistas, centrando-se em explicitar que a identidade sexual e de gênero dissidente não é diferente das majoritárias identidades heterossexual e cisgêneros. Para demonstrar tal ideia, utiliza o termo "homonormatividade". Enfatiza-se, portanto, que sujeitos da maioria cis/heterossexual não se diferem de LGBT, o que sugere outra perspectiva sobre identidades a serem assimiladas (Chan, 2018).

Portanto, estudos sobre ativismo LGBT, no cenário organizacional, encontram-se mais alinhados ao paradigma interpretativista e amparados em distintos referenciais teóricos que examinam os fenômenos específicos os quais pretende compreender, sendo, portanto, amplas as formas de abordagens e demonstradas as possibilidades de aplicações teóricas-metodológicas em natureza qualitativa. São diversos os tópicos dentro do ativismo que demandam aprofundamentos com olhares de várias lentes, como também se faz necessária a expansão desses estudos em natureza quantitativa, de modo a identificar conhecimentos que podem ser generalizados. E essa é a finalidade principal do próximo tópico: suscitar caminhos para que essa pesquisa ainda não tão fértil em âmbito nacional possa ser despertada.

\section{Agenda de Pesquisa}

Para atender ao objetivo proposto, apresentamos uma agenda de pesquisa pautada nas sugestões e discussões advindas dos artigos analisados neste trabalho (Tabela 4). Essa agenda baseia-se tanto nas proposições e perguntas recorrentes dos próprios artigos, ao longo de suas produções, quanto em questões que emergiram de reflexões dos autores deste texto sobre os achados do levantamento. 
Tabela 4: Relação de artigos que apresentaram agendas

\begin{tabular}{|c|c|}
\hline Artigo & Sugestão de pesquisas futuras \\
\hline Chuang et al. (2016) & $\begin{array}{l}\text { - Explorar efeitos mediadores e/ou moderadores das oportunidades políticas internas sobre os movimentos } \\
\text { intraorganizacionais; } \\
\text { - Verificar a influência das estruturas de contramovimento LGBT nas organizações; } \\
\text { - Analisar como a oportunidade cultural pode influenciar e seus efeitos no movimento interno; }\end{array}$ \\
\hline Githens (2012) & $\begin{array}{l}\text { - Descobrir a influência do estudo com grupos em modelos de desenvolvimento e mudança organizacional; } \\
\text { - Estudar casos de coalizões sustentáveis em que os esforços de concessão de benefícios a parceiros domésticos } \\
\text { LGBT fossem mais integrados aos sindicatos trabalhistas; } \\
\text { - Revelar as tensões e formas de apoio do RH a ativistas LGBT, usando conceitos críticos do desenvolvimento de } \\
\text { recursos humanos. }\end{array}$ \\
\hline McNulty et al. (2017) & $\begin{array}{l}\text { - Elaborar escopo mais amplo de questões e profundidade de cobertura para explorar os mecanismos de voz e } \\
\text { silenciamento de LGBT nas organizações, compreendendo, por exemplo, gerenciamento de riscos, igualdade de } \\
\text { voz e resultados do silêncio. }\end{array}$ \\
\hline Holland et al. (2016) & $\begin{array}{l}\text { - Explorar o assédio sexual masculino nas organizações fora dos EUA em interseccionalidade com questões de } \\
\text { raça e gênero. }\end{array}$ \\
\hline $\begin{array}{l}\text { Everly e Schwarz } \\
\text { (2014) }\end{array}$ & $\begin{array}{l}\text { - Identificar pontos específicos de como as políticas de RH para LGBT surgem, avaliando itens como: a influência } \\
\text { dos executivos dessa área; o papel dos consumidores; a pressão da cultura e das legislações locais etc. }\end{array}$ \\
\hline Willis (2010) & $\begin{array}{l}\text { - Analisar o significado das relações de amizade entre gêneros como base de apoio aos funcionários LGBT, } \\
\text { podendo explorar conexões entre os jovens; fontes de afirmação para transexuais em processo de transição; e } \\
\text { grupos que não têm uma única afiliação de identidade. }\end{array}$ \\
\hline $\begin{array}{l}\text { McFadden e Crowley- } \\
\text { Henry (2017) }\end{array}$ & $\begin{array}{l}\text { - Desenvolver em vários países mais estudos que explorem a voz dos trabalhadores transgênero, compreendendo } \\
\text { "se os atuais mecanismos de voz, como as redes LGBT, são adequados para representar trabalhadores } \\
\text { transgêneros, ou se grupos específicos desses funcionários devem existir" (McFadden \& Crowley-Henry, 2017, } \\
\text { p. 21). }\end{array}$ \\
\hline Köllen (2016) & $\begin{array}{l}\text { - Ampliar o espaço geográfico e de setores das pesquisas sobre aceitação pública da homossexualidade e as } \\
\text { possíveis práticas de RH para esses contextos organizacionais; } \\
\text { - Melhorar o entendimento sobre ambientes organizacionais favoráveis aos bissexuais e transexuais; } \\
\text { - Testar a utilização de quadro teórico proposto no artigo, baseado na teoria Heideggeriana, para avaliações de } \\
\text { recursos humanos e práticas de gerenciamento voltados à diversidade. }\end{array}$ \\
\hline $\begin{array}{l}\text { Drezner e Garvey } \\
\text { (2016) }\end{array}$ & $\begin{array}{l}\text { - Melhor compreender, na complexidade dos indivíduos, suas motivações para doações filantrópicas a causas } \\
\text { LGBT de modo a facilitar esse processo de captação de recursos. }\end{array}$ \\
\hline Chan (2018) & - Entender como grupos LGBT não políticos da sociedade civil contribuem para a política de identidade. \\
\hline Rengers et al. (2019). & $\begin{array}{l}\text { - Investigar conflitos de interesse compartilhados sobre a divulgação da sexualidade em ambientes de trabalho; } \\
\text { - Avaliar a inclusão sexual percebida em organizações por pessoas que preferem não divulgar sua opção sexual; } \\
\text { - Analisar os mecanismos da tolerância com a identidade sexual, os tensionamentos e consequências que Ihes } \\
\text { são advindos, e as maneiras disso ser trabalhado levando também em consideração a opinião dos grupos } \\
\text { majoritários. }\end{array}$ \\
\hline $\begin{array}{l}\text { Woodruffe-Burton e } \\
\text { Bairstow (2013) }\end{array}$ & $\begin{array}{l}\text { - Compreender mais profundamente como as lésbicas operam e negociam suas identidades no trabalho, podendo } \\
\text { iluminar possibilidades e desafios para as mulheres em funções de liderança. }\end{array}$ \\
\hline
\end{tabular}

Fonte: Elaborado pelos autores. 
Artigos apresentados no Tabela 4 estimulam novas pesquisas desde as oportunidades políticas e culturais internas às organizações em questões LGBT até seu acionamento pelas mais diversas formas de ativismos (Chuang et al., 2016; Everly \& Schwarz, 2014), uma vez que esse fenômeno não tem sido debatido em pesquisa nacionais, tais como: coalizões, mecanismos de voz (McFadden \& Crowley-Henry, 2017) e pressão de stakeholders. A agenda também aponta para as repercussões desses ativismos nas mudanças organizacionais, seja no que diz respeito ao surgimento e à adoção de políticas de $\mathrm{RH}$, seja nos enfrentamentos de preconceitos, discriminações e assédio, atentando ao cenário de interseccionalidades - opressão que se articula (Bilge, 2009) -, indicando investigar orientação sexual e identidade de gênero relacionadas a outros construtos identitários como cultura, etnia, crença religiosa, deficiência física e sensorial (Holland et al., 2016; Willis, 2010), de modo a possibilitar análises mais aproximadas do fenômeno real.

Nesse sentido, a importância da interseccionalidade para a compreensão das múltiplas formas de discriminação reside, longe de propor uma teoria globalizante de identidade, conforme alerta Bilge (2009), em sublinhar desigualdades sociais por intermédio de um enfoque integrado. "Ela refuta o enclausuramento e a hierarquização dos grandes eixos da diferenciação social que são as categorias de sexo/gênero, classe, raça, etnicidade, idade, deficiência e orientação sexual” (Bilge, 2009, p. 70). Tal perspectiva vem sendo evidenciada nos estudos organizacionais com LGBT, se considerada, por exemplo, questões como as dos LGBT expatriados (Paisley \& Tayar, 2015), ou mesmo a homogeneização em determinados territórios de consumo gay, onde se operam exclusões contra outros em função de marcadores como gênero, raça e classe social (Dalpian \& Silveira, 2020). Acrescenta-se que a questão LGBT vinculada à interseccionalidade nos estudos organizacionais nacionais dispõe de apenas um trabalho localizado na base SPELL (Dalpian \& Silveira, 2020). Assim, se propõe também o emprego da perspectiva interseccional em âmbito dos estudos envolvendo o ativismo LGBT no cenário nacional. Acrescenta-se que esse incentivo se dá ainda porque, considerando os artigos analisados não houve tendência à abordagem interseccional, mesmo em estudos envolvendo expatriados (McNulty et al., 2017) ou a discriminação perpetrada entre gays por conta de marcadores como a idade (Willis, 2010). Isso evidencia que é necessária uma maior problematização da categoria única do indivíduo LGBT (Paniza, 2020), pois se fala de homens gays, lésbicas negras, entre outras articulações, cada qual com suas especificidades, mas isso repercute em termos de movimento político, visto que o ativismo organizacional pode proporcionar uma fonte de dissidência e divisão entre as populações do acrônimo.

Como alguns artigos analisados neste estudo não apresentaram explícita e claramente agenda de pesquisa, atendo-se apenas aos seus achados ou ainda a implicações práticas e sugestões amplas e abertas (Brewster et al., 2014; Colgan \& McKearney, 2012; Murphy, 2012; Rhodes, 2017), infere-se, a partir da análise dos seus conteúdos e colaboração dos demais estudos, encaminhamentos considerados relevantes para o avanço do campo. 
Um tema que emergiu com considerável frequência, ainda que já apontado na revisão de $\mathrm{Ng}$ e Rumens (2017), e que teve expansão de publicações desde a década de 1990, foi o business case para a diversidade LGBT no ambiente de trabalho. Diferentemente do que demonstra a revisão supracitada sobre a publicação de artigos dedicados a diversidade LGBT no local de trabalho, igualdade e inclusão, a presente contribuição defende, também a partir das pesquisas de Drezner e Garvey (2016), Colgan e McKearney (2012) e Rhodes (2017), abordar agendas ativistas desvinculadas do business case em primeiro plano, ou seja, da necessidade de contribuir para a eficácia organizacional. A ideia seria explorar intervenções políticas empreendidas pelas mais diversas formas de ativismo LGBT em nome da ética para a justiça social mais igualitária nas organizações, sendo pertinente uma abordagem epistemológica crítica que possa, inclusive, avaliar a diversidade como ferramenta gerencial que acaba por privilegiar determinadas identidades na distribuição da justiça social, "[...] não significando abster-se de compreender ou explorar a lógica de negócios" (Rhodes, 2017, p. 543), até porque, como inferem Colgan e McKearney (2012), a análise dicotômica de justiça social e diversidade dirigida por business case pode ser inútil.

Nesse sentido, na necessidade de avaliar implicações políticas e práticas da justiça social quando o argumento do business case assume o primeiro plano em defesa da diversidade de orientação sexual e identidade de gênero nas organizações, como é comum que se dê dessa forma, o que poderia estar sendo negligenciado? Quando se pensa, por exemplo, essa questão em associação à ética, seria o business case projetado para esse fim? Esse modelo é o mais efetivo? Para Colgan e McKearney (2012), diferentemente do que ocorreu na década de 1990, a justiça social, recentemente e em estudos de gênero, tem sido abordada pela responsabilidade social corporativa por melhor compreender essas problemáticas e conectá-la a contextos globais? Não se estaria substituindo um utilitarismo por outro?

Dentre as abordagens relevantes de expandir, destaca-se a adoção da analítica queer - "que defende uma visão pós-identitária e fragmentada em relação ao pensamento identitário/binário hegemônico sobre a sexualidade e os estudos de gênero" - como análise crítica do campo organizacional (Souza \& Carrieri, 2010, p. 47). Além de pouco explorada nas pesquisas, a analítica queer poderia colaborar para responder a problemáticas baseadas em visões heterocêntricas que impactam as organizações, refletindo em: direitos e compensações menores quando comparados aos seus pares não LGBT (Willis, 2010); conflitos na negociação de identidades, a depender de quais sejam as práticas sociais situadas e seus respectivos riscos em ambientes heteronormativos (Woodruffe-Burton \& Bairstow, 2013); identificação de práticas políticas que possam mover famílias não tradicionais das margens para o centro da justiça social (Murphy, 2012); exploração das alianças não por identidades estáveis, mas para romper com as normas não hegemônicas, entendendo como pessoas pertencentes a grupos marginalizados se relacionam e se apoiam nas suas lutas (Brewster et al., 2014; Willis, 2010). Desse modo, não se desconsideram ativismos subversivos, os quais trabalham questões sociais mais amplas, possibilitando incluir identidades não binárias (Githens \& Aragon, 2009). 
Por fim, outros pontos, também pertinentes, são a inclusão LGBT em organizações religiosas, de voluntariado ou de terceiro setor e ativismos propagados em formas organizacionais como os clubes esportivos e comunidades online (Chan, 2018; Rengers et al., 2019), além de avaliar a solução para essas questões do ponto de vista de trabalhadores heterossexuais (Rengers et al., 2019).

Observa-se que mesmo nos estudos internacionais, essa temática em vários artigos foi abordada de forma secundária, reforçando ainda mais sua pertinência de aprofundamento. Além disso, no campo de estudos organizacionais brasileiros, envolvendo LGBT, evidencia-se a lacuna e necessidade da investigação sobre ativismo. O que existe de avanços não envolve movimentos políticos internos às organizações, desfavorecendo a produção e divulgação de conteúdos que poderiam inspirar outros grupos a estabelecerem lutas semelhantes, contribuindo no processo de transformação social, tendo em vista as influências que o social tem no organizacional e vice-versa. Assim, espera-se que esse artigo possa aguçar o ânimo dos cientistas das ciências sociais aplicadas nessa empreitada.

\section{Considerações Finais}

Este estudo, conduzido a partir de revisão sistemática da literatura, originada em levantamento junto à Scopus de 2010 a 2019, visou respondeu à seguinte questão: "qual tem sido o debate acadêmico sobre ativismo LGBT nas organizações?". Conclui-se, com base na revisão desenvolvida que o ativismo LGBT nas organizações, além de iniciativa recente no mundo organizacional, tem incipiência de interesse de pesquisa por parte da academia, fato que se comprova com base no número de publicações localizadas, especificamente associadas ao fenômeno, bem como pela maioria das revistas terem fator de impacto moderado.

$\mathrm{Na}$ análise realizada, constatou-se que foi recorrente o paradigma interpretativista. Nesse sentido, a natureza qualitativa das pesquisas se fez mais expressiva que as demais abordagens. Quanto aos fundamentos teóricos, foram contempladas categorias como gênero, assédio, diversidade e estereótipos, ainda que constatada relativa emergência de estudos organizacionais com perspectivas mais políticas. Observou-se que características do ativismo organizacional favorecem a abordagem do tipo "informal internamente responsiva", ou seja, tratam-se, em sua maioria, de grupos que, estruturados informalmente em um contexto institucional maior de uma organização, possuíam seus objetivos alinhados à efetividade organizacional (Githens \& Aragon, 2009). Desse modo, mesmo que se apresentando de forma ainda bastante utilitarista, esses grupos conseguem auferir conquistas ao fazer justiça social voltada às minorias sexuais num cenário com menor risco de retaliações à carreira desses ativistas, valendo-se, para isso, de estratégias majoritariamente alinhadas à lógica do business case em detrimento do argumento da defesa da ética, como primeiro plano, para sua efetividade.

Em termos de agenda deste artigo, apresentam-se sugestões para pesquisas futuras, como: investigar desde as oportunidades políticas e culturais internas às organizações em questões LGBT até o seu estímulo pelas 
mais diversas formas de ativismos, a exemplo de coalizões, mecanismos de voz e pressão de stakeholders; avaliar repercussões desses ativismos nas mudanças organizacionais, seja no que diz respeito ao surgimento e adoção de políticas de $\mathrm{RH}$, seja nos enfrentamentos de preconceitos, discriminações e assédio, atentando ao cenário de interseccionalidades.

Além disso, propõe-se ampliar a utilização da abordagem epistemológica crítica para permitir analisar implicações das intervenções políticas empreendidas como ferramenta gerencial que pode privilegiar determinadas identidades na distribuição da justiça social. Sugere-se, ainda, a adoção da analítica queer, que, além de pouco explorada, poderia colaborar para responder a problemáticas baseadas em visões heterocêntricas que impactam as organizações, refletindo em direitos e compensações menores a pessoas com expressões identitárias diferentes da convencional, conflitos na negociação de identidades e exploração das alianças não por identidades estáveis, entendendo como pessoas pertencentes a grupos marginalizados se relacionam e se apoiam nas suas lutas.

Ressalvamos aqui nossa limitação ao decidir por trabalhar com uma única base de dados, ainda que ampla. Assim, os artigos analisados são parte do que já existe publicado. Nessa sequência, esclarecemos que não debatemos a identidade travesti, que é comum na realidade nacional, mas que apresenta aspectos principalmente de classe social diferentes dos transexuais, o que potencializa o estigma e a vulnerabilidade dessas vidas, e impacta diretamente em questões de trabalho, interseccionando a baixa renda com a dissidência de gênero (Carvalho, 2018).

Diante dos achados, é importante frisar que este estudo de revisão sistemática é pioneiro por tratar de ativismo LGBT, identificando linhas específicas para sua investigação em estudos organizacionais. Tal contribuição é importante, principalmente, quando se reconhece a política como importante via para esse enfrentamento e o ativismo como meio promotor das alianças, que se opõem às forças e aos regimes disciplinadores e reguladores, os quais expõem vidas a condições precárias (Butler 2018b). Desse modo, o conhecimento aqui reunido pode auxiliar não apenas estimulando o debate e investigação na academia brasileira, mas também na prática de ação direta e gerencial, isto é, não apenas como fonte de referência para pesquisas sobre LGBT nas organizações, mas incidindo sobre público-alvo de militantes da causa, profissionais de recursos humanos, líderes empresariais e governamentais, estudiosos, enfim, todos aqueles preocupados com a inclusão e a igualdade nas organizações.

\section{Referências}

Aksoy, C. G., Carpenter, C. S., Frank, J., \& Huffman, M. L. (2018). Gay glass ceilings: sexual orientation and workplace authority in the UK. Journal of Economic Behavior \& Organization, 159, 167-180.

Anteby, M., \& Anderson, C. (2014). The shifting landscape of LGBT organizational research. Research in Organizational Behavior, 34, 3-25. 
Baggio, M. C. (2017). About the relation between transgender people and the organizations: new subjects for studies on organizational diversity. REGE - Revista de Gestão, 24(4), 360-370.

Barrantes, R. J., \& Eaton, A. A. (2018). Sexual orientation and leadership suitability: how being a gay man affects perceptions of fit in gender-stereotyped positions. Sex Roles, 79(9-10), 549-564.

Bilge, S. (2009). Théorisations féministes de l'intersectionnalité. Diogène, 1(225), 70-88.

Bierema, L. L. (2010). Critical organization development for human resource development and adult education. Malabar: Krieger.

Brewster, M. E., Velez, B. L., Mennicke, A., \& Tebbe, E. (2014). Voices from beyond: a thematic content analysis of transgender employees' workplace experiences. Psychology of Sexual Orientation and Gender Diversity, 1(2), 159-169.

Briscoe, F., Chin, M. K., \& Hambrick, D. C. (2014). CEO ideology as an element of the corporate opportunity structure for social activists. Academy of Management Journal, 57(6), 1786-1809.

Butler, J. (2018a). Corpos que pesam: sobre os limites discursivos do "sexo". In G. L. Louro (Ed.). O corpo educado: pedagogias da sexualidade (2a. ed., pp. 110-125). Belo Horizonte: Autêntica.

Butler, J. (2018b). Corpos em aliança e a política das ruas: notas para uma teoria performativa de assembleia. Rio de Janeiro: Civilização Brasileira.

Caproni Neto, H. L., Saraiva, L. A. S., \& Bicalho, R. D. A. (2014). Diversidade sexual nas organizações: um estudo sobre coming out. Revista Pensamento Contemporâneo em Administração, 8(1), 86-103.

Carrieri, A. D. P., Souza, E. M. d., \& Aguiar, A. R. C. (2014). Trabalho, violência e sexualidade: estudo de lésbicas, travestis e transexuais. Revista de Administração Contemporânea, 18(1), 78-95.

Carvalho, M. (2018). "Travesti", "mulher transexual", "homem trans" e "não binário": interseccionalidades de classe e geração na produção de identidades políticas. Cadernos Pagu, (52).

Chan, P. M. (2018). Desexualizing sexual identity politics: the framing of pro-LGBT Christian organizations in Hong Kong. Sexuality \& Culture, 22(4), 1452-1465.

Chuang, Y. T., Church, R., \& Hu, C. (2016). Effects of movements and opportunities on the adoption of same-sex partner health benefits by corporations. Journal of Management, 44(7), 2766-2800.

Colgan, F., \& McKearney, A. (2012). Visibility and voice in organisations: lesbian, gay, bisexual and transgendered employee networks. Equality, Diversity and inclusion: an international journal, 31(4), 359-378.

Collins, P. H. (2007). Pushing the boundaries or business as usual? Race, class, and gender studies and sociological inquiry. In C. Calhoun (Ed.). Sociology in America: a history (pp. 572-604). Chicago: University of Chicago Press.

Creed, W. D., \& Scully, M. A. (2000). Songs of ourselves: employees' deployment of social identity in workplace encounters. Journal of Management Inquiry, 9(4), 391-412. 
Cronin, P., Ryan, F., \& Coughlan, M. (2008). Undertaking a literature review: a step-by-step approach. British Journal of Nursing, 17(1), 38-43.

Dalpian, P. R. C., \& Silveira, T. D. (2020). Locais de mercado, diversidade e exclusão interseccional. Cadernos Ebape.BR, 18(2), 377-390.

Den Hond, F., \& De Bakker, F. G. (2007). Ideologically motivated activism: how activist groups influence corporate social change activities. Academy of management review, 32(3), 901-924.

Diani, M., \& McAdam, D. (Eds.). (2003). Social movements and networks: relational approaches to collective action. Oxford: Oxford University Press.

Diniz, A. P. R., Carrieri, A. D. P., Gandra, G., \& Bicalho, R. A. (2013). Políticas de diversidade nas organizações: as relações de trabalho comentadas por trabalhadores homossexuais. Revista Economia \& Gestão, 13(31), 93-114.

Drezner, N. D., \& Garvey, J. C. (2016). LGBTQ alumni philanthropy: Exploring (un) conscious motivations for giving related to identity and experiences. Nonprofit and Voluntary Sector Quarterly, 45(1_suppl), 52S-71S.

Dundon, T., Wilkinson, A., Marchington, M., \& Ackers, P. (2004). The meanings and purpose of employee voice. The International Journal of Human Resource Management, 15(6), 1149-1170.

Everly, B. A., \& Schwarz, J. L. (2015). Predictors of the adoption of LGBT friendly HR policies. Human Resource Management, 54(2), 367-384.

Foucault, M. (1995). O sujeito e o poder. In H. L. Dreyfus, P. Rabinow, \& M. Foucault. (Eds.). Uma trajetória filosófica: para além do estruturalismo e da hermenêutica (pp. 231-149). Rio de Janeiro: Forense Universitária.

Freitas, M. E. d. (2015). Contexto, políticas públicas e práticas empresariais no tratamento da diversidade no Brasil. Revista Interdisciplinar de Gestão Social, 4(3), 87-135.

Frooman, J. (1999). Stakeholder influence strategies. Academy of Management Review, 24(2), 191-205.

Garcia, A., \& Souza, E. M. (2010). Sexualidade etrabalho: estudo sobre a discriminação de homossexuais masculinos no setor bancário. Revista de Administracão Pública, 44(6), 1353-1377.

Githens, R. P. (2012). Organization change and social organizing strategies: employee initiated organization development. Human Resource Development Quarterly, 23(4), 487-518.

Githens, R. P., \& Aragon, S. R. (2009). LGBT employee groups: goals and organizational structures. Advances in Developing Human Resources, 11(1), 121-135.

Gomes, R., \& Felix, B. (2019). O self no armário: uma teoria fundamentada sobre o silêncio de gays e de lésbicas no ambiente de trabalho. Cadernos Ebape.BR, 17(2), 375-388.

Holland, K. J., Rabelo, V. C., Gustafson, A. M., Seabrook, R. C., \& Cortina, L. M. (2016). Sexual harassment against men: examining the roles of feminist activism, sexuality, and organizational context. Psychology of Men \& Masculinity, 17(1), 17-29. Irigaray, H. A. R., \& Freitas, M. E. (2011). Sexualidade e organizações: estudo sobre lésbicas no ambiente de trabalho. Organizações \& Sociedade, 18(59), 625-641. 
Irigaray, H. A., \& Freitas, M. E. d. (2013). Estratégia de sobrevivência dos gays no ambiente de trabalho. Revista Psicologia Política, 13(26), 75-92.

Irigaray, H. A. R., Saraiva, L. A. S., \& Carrieri, A. D. P. (2010). Humor e discriminação por orientação sexual no ambiente organizacional. Revista de Administração Contemporânea, 14(5), 890-906.

King, B. G., \& Pearce, N. A. (2010). The contentiousness of markets: politics, social movements, and institutional change in markets. Annual Review of Sociology, 36, 249-267.

Köllen, T. (2016). Lessening the difference is more - The relationship between diversity management and the perceived organizational climate for gay men and lesbians. The International Journal of Human Resource Management, 27(17), 1967-1996.

Larsen, P., \& Rathemacher, A. (2017). Web of Science vs. Scopus: presentation for the URI Deans' Council. Recuperado em 13 abril, 2020, de https://digitalcommons. uri.edu/cgi/viewcontent.cgi?article=1048\&context=lib_ts_presentations

Louro, G. L. (1997). Gênero, sexualidade e educação: uma perspectiva pós-estruturalista. (6a. ed.). Petrópolis: Vozes.

Martinez, L. R., Sawyer, K. B., \& Wilson, M. C. (2017). Understanding the experiences, attitudes, and behaviors of sexual orientation and gender identity minority employees. Journal of Vocational Behavior, 103, 1-6.

McAdam, D. (1986). Recruitment to high-risk activism: the case of freedom summer. American Journal of Sociology, 92(1), 64-90.

McFadden, C. (2015). Lesbian, gay, bisexual, and transgender careers and human resource development: a systematic literature review. Human Resource Development Review, 14(2), 125-162.

McFadden, C., \& Crowley-Henry, M. (2017). 'My People': the potential of LGBT employee networks in reducing stigmatization and providing voice. The International Journal of Human Resource Management, 29(5), 1056-1081.

McNulty, Y., McPhail, R., Inversi, C., Dundon, T., \& Nechanska, E. (2018). Employee voice mechanisms for lesbian, gay, bisexual and transgender expatriation: the role of Employee-Resource Groups (ERGs) and allies. The International Journal of Human Resource Management, 29(5), 829-856.

Moura, R. G. d., \& Nascimento, R. P. (2020). O estigma da feminilidade nas organizações: um estudo a partir da visão de sujeitos gays. Revista Eletrônica de Ciência Administrativa, 19(2), 203-226.

Murphy, R. P. (2012). United Airlines is for lovers? Flight attendant activism and the family values economy in the 1990s. Radical History Review, 2012(112), 100-112.

Ng, E., \& Rumens, N. (2017). Diversity and inclusion for LGBT workers: current issues and new horizons for research. Canadian Journal of Administrative Sciences, 34(2), 109-120.

Oberfield, Z. W. (2014). Accounting for time: comparing temporal and atemporal analyses of the business case for diversity management. Public Administration Review, 74(6), 777-789.

Olsson, J., \& Hysing, E. (2012). Theorizing inside activism: understanding policymaking and policy change from below. Planning Theory \& Practice, 13(2), 257-273. 
Paisley, V., \& Tayar, M. (2016). Lesbian, gay, bisexual and transgender (LGBT) expatriates: an intersectionality perspective. The International Journal of Human Resource Management, 27(7), 766-780.

Paniza, M. R. D. (2020). Entre a emergência, a submersão e o silêncio: LGBT como categoria de pesquisa em Administração. Cadernos Ebape.BR, 18(1), 13-27.

Paula, A. P. P. d. (2016). Para além dos paradigmas nos Estudos Organizacionais: o círculo das matrizes epistêmicas. Cadernos Ebape.BR, 14(1), 24-46.

Pompeu, S. L. E., \& de Souza, E. M. (2018). A produção científica sobre sexualidade nos estudos organizacionais: uma análise das publicações realizadas entre 2005 e 2014. Organizações \& Sociedade, 25(84), 50-67.

Pompeu, S. L. E., \& Souza, E. M. d. (2019). A discriminação homofóbica por meio do humor: naturalização e manutenção da heteronormatividade no contexto organizacional. Organizações \& Sociedade, 26(91), 645-664.

Preciado, B. (2011). Multidões queer: notas para uma política dos "anormais". Revista Estudos Feministas, 19(1), 11-20.

Rabelo, A. M., \& Nunes, S. C. (2017). "Sair ou ficar no armário"? Eis a questão! Estudo sobre as razões e os efeitos do coming out no ambiente de trabalho. E\&GEconomia \& Gestão, 17(48), 82-97.

Raeburn, N. C. (2004). Working it out: the emergence and diffusion of the workplace movement for lesbian, gay, and bisexual rights. Authority in Contention, 25, 187-230.

Ragins, B. R., \& Cornwell, J. M. (2001). Pink triangles: antecedents and consequences of perceived workplace discrimination against gay and lesbian employees. Journal of Applied Psychology, 86(6), 1244-1261.

Rengers, J. M., Heyse, L., Otten, S., \& Wittek, R. P. (2019). "It's not always possible to live your life openly or honestly in the same way"- Workplace inclusion of lesbian and gay humanitarian aid workers in Doctors without Borders. Frontiers in Psychology, 10(320), 1-67.

Rhodes, C. (2017). Ethical praxis and the business case for LGBT diversity: political insights from Judith Butler and Emmanuel Levinas. Gender, Work \& Organization, 24(5), 533-546.

Rumens, N. (2008). Working at intimacy: gay men's workplace friendships. Gender, Work \& Organization, 15(1), 9-30.

Rubin, G. (1984). Thinking sex: Notes for a radical theory of the politics of sexuality. In C. S. Vance (Ed.). Pleasure and danger: exploring female sexuality (pp. 267-317). Boston: Routledge and Kegan Paul.

Saraiva, L. A. S., \& Irigaray, H. A. R. (2009). Políticas de diversidade nas organizações: uma questão de discurso?. Revista de Administração de Empresas, 49(3), 337-348.

Schmidt, S. W., Githens, R. P., Rocco, T. S., \& Kormanik, M. B. (2012). Lesbians, gays, bisexuals, and transgendered people and human resource development: an examination of the literature in adult education and human resource development. Human Resource Development Review, 11(3), 326-348.

Schneiberg, M., \& Lounsbury, M. (2008). Social movements and institutional analysis. In R. Greenwood et al. (Eds.). The handbook of organizational institutionalism (pp. 650-672). London: Sage.

Schussman, A., \& Soule, S. A. (2005). Process and protest: accounting for individual protest participation. Social Forces, 84(2), 1083-1108. 
Scopus (2020). Content coverage guide. Recuperado em 15 fevereiro, 2020, de https://www.elsevier.com/?a=69451

Scully, M. A., Creed, W. D., \& Ventresca, M. J. (1998). More than switch persons on the tracks of history: situated agency and contested legitimacy during the diffusion of domestic partner benefits. Anais do "Annual Meeting of the Academy of Management", San Diego, CA, Estados Unidos.

Silva, A., Bastos, G. M. F., Lima, T. C. B., Ferraz, S. F. S., \& Cabral, A. C. A. (2013). Sentido do trabalho e diversidade: um estudo com homossexuais masculinos. Revista ADM.MADE, 17(2), 85-105.

Siqueira, M. V. S., \& Andrade, A. (2012). Em busca de uma pedagogia gay no ambiente de trabalho. In M. E. Freitas, \& M. Dantas (Eds.). Diversidade sexual no trabalho (pp. 99-120). São Paulo: Cengage Learning.

Siqueira, M. V. S., Saraiva, L. A. S., Carrieri, A. P., Lima, H. K. B., \& Andrade, A. J. (2009). Homofobia e violência moral no trabalho no Distrito Federal. Organizações \& Sociedade, 16(50), 447-461.

Siqueira, M. V. S., \& Zauli-Fellows, A. (2006). Diversidade e identidade gay nas organizações. GESTÃO.Org - Revista Eletrônica de Gestão Organizacional, 4(3), 70-81.

Soule, S. A. (2012). Social movements and markets, industries, and firms. Organization Studies, 33(12), 1715-1733.

Souza, E. M. (2017). A Teoria Queer e os Estudos Organizacionais: revisando conceitos sobre identidade. Revista de Administração Contemporânea, 21(3), 308-326.

Souza, E. M., \& Carrieri, A. D. P. (2010). A analítica queer e seu rompimento com a concepção binária de gênero. Revista de Administração Mackenzie, 11(3), 46-70.

Souza, E. M., Silva, A. R. L. D., \& Carrieri, A. D. P. (2012). Uma análise sobre as políticas de diversidade promovidas por bancos. Psicologia \& Sociedade, 24(2), 315-326.

Trau, R. N. (2015). The impact of discriminatory climate perceptions on the composition of intraorganizational developmental networks, psychosocial support, and job and career attitudes of employees with an invisible stigma. Human Resource Management, 54(2), 345-366.

Webster, J. R., Adams, G. A., Maranto, C. L., Sawyer, K., \& Thoroughgood, C. (2017). Workplace contextual supports for LGBT employees: a review, meta analysis, and agenda for future research. Human Resource Management, 57(1), 193-210.

Willis, P. (2010). Connecting, supporting, colliding: the work-based interactions of young LGBQ-identifying workers and older queer colleagues. Journal of LGBT Youth, 7(3), 224-246.

Woodruffe-Burton, H., \& Bairstow, S. (2013). Countering heteronormativity: exploring the negotiation of butch lesbian identity in the organisational setting. Gender in Management: An International Journal, 28(6), 359-374. 